\title{
Rancangan Sistem Kontrol dan Monitoring Panel LVSDP Menggunakan Mikrokontroler Berbasis Personal Computer di Bandara Sultan Aji Muhammad Sulaiman Sepinggan Balikpapan
}

\author{
Kustori $^{1}$ \\ Supriadi \\ ${ }^{1}$ Program Studi Teknik Listrik Bandar Udara \\ Politeknik Penerbangan Surabaya \\ Jl. Jemur Andayani I/73 Surabaya
}

\begin{abstract}
Abstrak
Pada jam operasional Bandara Internasional Sultan Aji Muhammad Sulaiman Seping gan Balikpapan sering dijumpai komplain pihak terminal bandara dan pihak tenant yang memberitahu teknisi listrik tentang masalah tidak adanya power listrik menyuplai beban di suatu titik terminal bandara. Untuk menanggapi hal tersebut, seorang teknisi harus menuju ke lokasi untuk melakukan pengecekan. Hal yang dilakukan teknisi ini dipandang kurang efisien karena belum adanya kontrol dan monitoring jarak jauh secara otomatis menggunakan PC. Untuk mengatasi hal tersebut, penulis bermaksud untuk merancang sebuah alat kontrol dan monitoring panel LVSDP secara otomatis menggunakan mikrokontroller dengan bantuan sensor arus ACS-712 dan sensor tegangan H1 1AA1. Setelah diketahui nilai arus dan tegangan yang menuju ke beban selanjutnya akan ditampilkan pada PC menggunakan software Visual Basic sebagai Human Machine Interface.
\end{abstract}

Kata-Kata Kunci: Sistem Kontrol, Monitoring Panel LVSDP, Mikrokontroler.

\section{Latar Belakang Masalah}

Bandar Udara Sultan Aji Muhammad Sulaiman Sepinggan adalah Bandar Udara Internasional yang terletak di Balikpapan, Kalimantan Timur. Bandar Udara ini memiliki Kode ICAO nya WALL dan Kode IATA nya BPN. Bandar Udara Sultan Aji Muhammad Sulaiman Sepinggan Balikpapan merupakan Bandar Udara terbesar ke-4 dari 13 Bandar Udara yang dikelola PT. Angkasa Pura 1 Persero. Bandar Udara Sultan Aji Muhammad Sulaiman Sepinggan memiliki terminal baru yang lebih luas 110.000 meter persegi dari sebelumnya yang hanya 17.000 meter persegi.

Bandar Udara Sultan Aji Muhammad Sulaiman Sepinggan Balikpapan berlangganan energi listrik dari PT. PLN sebagai catu daya utama dengan tegangan menengah yang diperoleh dari 2 sumber berbeda yang didistribusikan menuju Panel MVMDP (Medium Voltage Main Distribution Panel) hingga menuju ke LVSDP (Low Voltage Sub Distribution Panel). Sumber pertama diperoleh dari pembangkit listrik tenaga diesel (PLTD) Batakan yang mempunyai kapasitas daya sebesar $3645 \mathrm{kVa}$ menggunakan tegangan $20 \mathrm{Kv}$ yang terhubung ke gedung Power Station lama. Sumber kedua diperoleh dari pembangkit listrik tenaga diesel (PLTD) Gunung Malang dengan kapasitas $8660 \mathrm{kVa}$ menggunakan tegangan 20kVa yang terhubung ke gedung Power Station baru.

Kondisi yang ada di lapangan saat ini, sistem kontrol dan monitoring pada panel LVSDP (Low Voltage Sub Distribution Panel) masih dilakukan secara manual. Teknisi listrik baru menuju ke lapangan jika ada laporan komplain dari pihak terminal atau pihak tenant yang memberi tahu adanya troubleshooting contohnya tidak adanya power listrik sehingga teknisi listrik harus ke lapangan untuk melakukan pengecekan. Kejadian ini hampir terjadi setiap hari 
dalam hitungan sebulan. Ditambah lagi terbatasnya jumlah teknisi listrik yaitu 22 orang yang terbagi menjadi 3 kelompok setiap harinya. Melihat kondisi seperti itu dibutuhkan suatu Rancangan sistem kontrol dan monitoring secara otomatis pada panel LVSDP (Low Voltage Sub Distribution Panel) berbasis komputerisasi yang diletakan di MPH (Main Power House) sehingga lebih efektif dan efisien waktu.

Berdasarkan latar belakang tersebut muncul rumusan masalah, "Bagaimana cara pengaplikasian Arduino Nano untuk mengontrol dan memonitoring panel LVSDP ( Low Voltage Sub Distribution Panel )? Bagaimana cara pengiriman data arus dan tegangan ke tampilan Personal Computer?"

\section{Kondisi Saat ini}

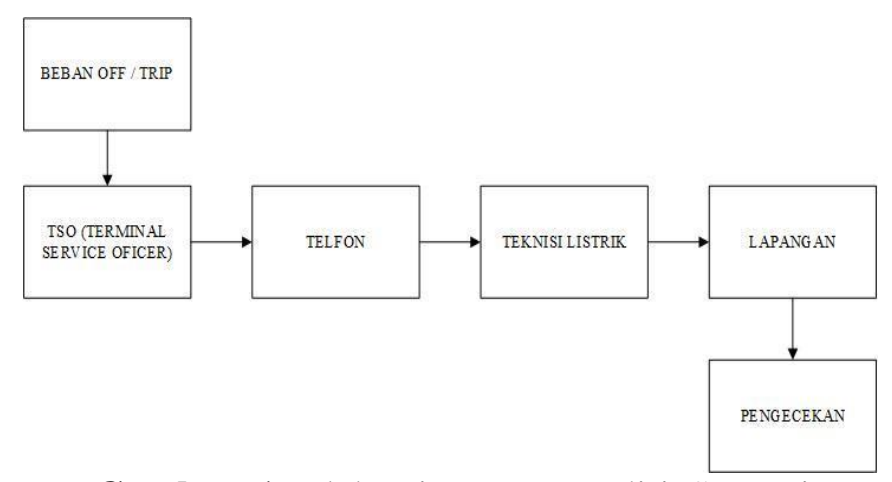

Gambar 1. Blok Diagram Kondisi Saat Ini

Kondisi yang ada di lapangan saat ini, sistem kontrol dan monitoring pada panel LVSDP (Low Voltage Sub Distribution Panel) masih dilakukan secara manual. Teknisi listrik baru menuju ke lapangan jika ada laporan komplain dari pihak terminal atau pihak tenant yang memberi tahu adanya masalah contohnya tidak adanya power listrik sehingga teknisi listrik harus ke lapangan untuk melakukan pengecekan. Kejadian ini hampir terjadi setiap hari dalam hitungan sebulan. Ditambah lagi terbatasnya jumlah teknisi listrik yaitu 22 orang yang terbagi menjadi 3 kelompok setiap harinya.

\section{Kondisi Yang Diinginkan}

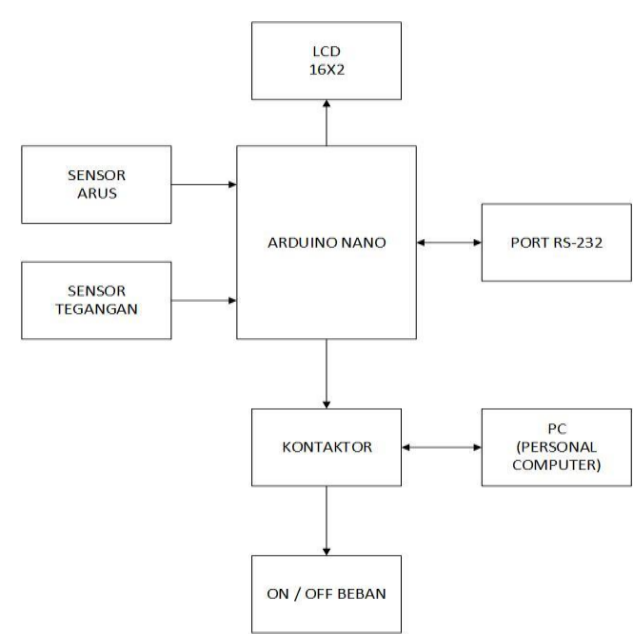

Gambar 2. Blok Digram Rancangan 
Dari Blok diagram tersebut Cara kerja dari rancangan alat ini dimulai dari Power supply yang digunakan untuk sumber tegangan yang diperlukan untuk beberapa blok. Unit input yaitu sensor arus ACS-712 dan sensor tegangan H11AA1 yang bekerja sebagai pembaca nilai arus dan tegangan. Arduino Nano sebagai piranti elektronik yang didalamnya terdapat chip mikrokontroler ATmega328 yang berfungsi sebagai pengolah sinyal input dan memprosesnya untuk mengatur jalannya alat yang dioperasikan. Setelah diproses sinyal keluaran dari Arduino diterima oleh LCD (Liquid Crystal Display) 16x2 sebagai penampil nilai arus dan tegangan sementara yang menuju ke beban. Dari Arduino data tersebut dikirim ke PC (Personal Computer) dengan bantuan komunikasi serial port RS-232. Di dalam tampilan PC (Personal Computer) selanjutnya akan di interface kan dengan Visual Basic. Jika di PC (Personal Computer) terbaca ada beban yang trip maka PC (Personal Computer) akan mengontrol untuk menyalakan power yang menuju ke beban yang dikirim melalui komunikasi serial port RS-232 dan selanjutnya akan diolah oleh Arduino Nano. Setelah sinyal inputan diolah, maka Arduino Nano akan dapat menggerakan kontaktor, karena prinsip kerja nya membutuhkan tegangan untuk dapat mengontrol suatu peralatan yang membutuhkan tegangan lebih besar. Kontaktor disini berfungsi sebagai saklar untuk ON/ OFF beban.

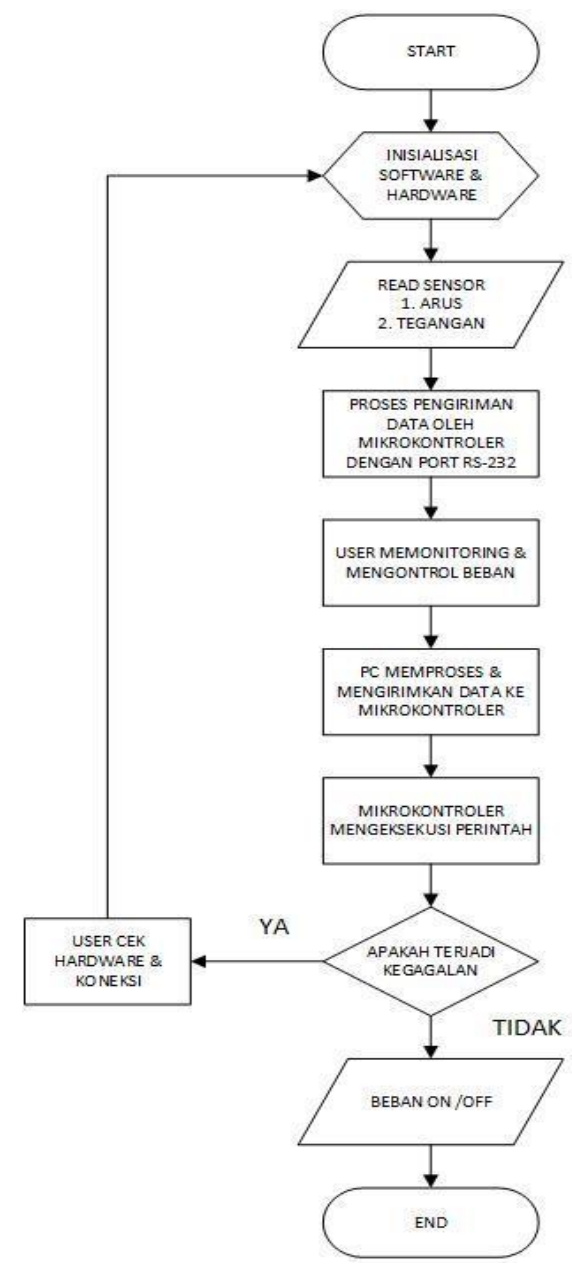

Gambar 3 Flowchart Rancangan Alat 


\section{Pengujian dan Analisis Hasil Pengujian Pengujian Power Supply}

Power Supply pada rancangan ini menggunakan rangkaian diode bridge ditambahkan regulator sebagai penstabil tegangan. Fungsi Power Supply pada rancangan ini adalah sebagai sumber tegangan untuk rangkaian kontrol Arduino sebagai pengganti battery charger yang memiliki fungsi sebagai catu daya untuk menyuplai rangkaian kontrol yang ada.

Tegangan input dari power supply yang digunakan tidaklah stabil 220 Vac dikarenakan losses tegangan. Hal ini disebabkan beberapa hal seperti tahanan kabel dan yang lainnya tetapi masih tetap pada batas toleransi karena tegangan ini berasal dari sumber PLN. Untuk tegangan output mendapatkan selisih yang mungkin disebabkan karena losses dari rangkaian Power Supply itu sendiri.

Tabel 1 Hasil Pengujian Power Supply 5 Vdc

\begin{tabular}{|c|c|c|}
\hline Percobaan & Tegangan Input (v) & Tegangan Output (v) \\
\hline 1 & $217 \mathrm{Vac}$ & $5.00 \mathrm{Vdc}$ \\
\hline 2 & $223 \mathrm{Vac}$ & $5.00 \mathrm{Vdc}$ \\
\hline 3 & $220 \mathrm{Vac}$ & $5.00 \mathrm{Vdc}$ \\
\hline
\end{tabular}

Setelah dilakukan beberapa pengujian, data yang di dapat menunjukan bahwa tegangan input dan output power supply telah sesuai dengan yang dibutuhkan.

\section{Pengujian Sensor Tegangan}

Sensor tegangan adalah sensor yang digunakan oleh penulis untuk membaca tegangan pada sistem. Sebelum digunakan, sensor ini diuji terlebih dahulu untuk mengetahui apakah sensor sudah bekerja sesuai yang diinginkan atau belum.

Tabel 2 Hasil Pengujian Sensor Tegangan

\begin{tabular}{|c|c|c|}
\hline Percobaan & $\begin{array}{c}\text { Tegangan yang } \\
\text { Tersensor }\end{array}$ & $\begin{array}{c}\text { Tegangan yang } \\
\text { Diukur Dengan } \\
\text { Avometer }\end{array}$ \\
\hline 1 & $222 \mathrm{~V}$ & $215 \mathrm{~V}$ \\
\hline 2 & $217 \mathrm{~V}$ & $217 \mathrm{~V}$ \\
\hline 3 & $220 \mathrm{~V}$ & $215 \mathrm{~V}$ \\
\hline
\end{tabular}

Setelah dilakukan beberapa pengujian, data yang di dapat menunjukan bahwa rangkaian sensor tegangan dapat bekerja dengan baik telah sesuai dengan yang dibutuhkan.

\section{Pengujian Sensor Arus}

Sensor tegangan adalah sensor yang digunakan oleh penulis untuk membaca tegangan pada sistem. Sebelum digunakan, sensor ini diuji terlebih dahulu untuk mengetahui apakah sensor sudah bekerja sesuai yang dïnginkan atau belum.

Tabel 3 Hasil Pengujian Sensor Arus 


\begin{tabular}{|c|c|c|c|}
\hline No & Nama Beban & $\begin{array}{c}\text { Hasil } \\
\text { Pengukuran } \\
\text { Tang Ampere }\end{array}$ & $\begin{array}{c}\text { Hasil } \\
\text { Pembacaan } \\
\text { Sensor Arus }\end{array}$ \\
\hline 1 & Lampu Pijar 40 W & $0.06 \mathrm{~A}$ & $0.04 \mathrm{~W}$ \\
\hline 2 & Lampu Pijar 75 W & $0.25 \mathrm{~A}$ & $0.24 \mathrm{~W}$ \\
\hline 3 & Lampu Pijar 100 W & $0.39 \mathrm{~A}$ & $0.45 \mathrm{~W}$ \\
\hline
\end{tabular}

Setelah dilakukan beberapa pengujian, data yang di dapat menunjukan bahwa rangkaian sensor arus dapat bekerja dengan baik meskipun ada selisih nol koma sekian antara Pengukuran Tang Ampere dengan pembacaan sensor arus.

\section{Pengujian LCD $16 \times 2$}

LCD $16 \times 2$ adalah salah satu parameter yang digunakan oleh penulis untuk membaca arus dan tegangan pada sistem. Sebelum digunakan, LCD dengan dimensi 16 x 2 ini diuji terlebih dahulu untuk mengetahui apakah sudah bekerja sesuai yang diinginkan atau belum.

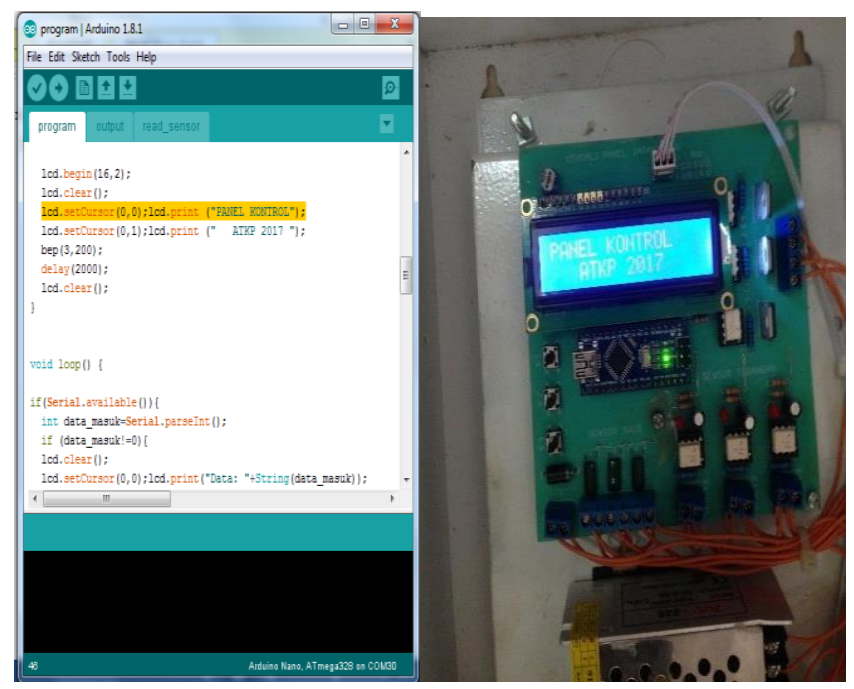

Gambar 4. LCD 16X2

Setelah dilakukan pengujian, bilangan yang muncul pada LCD 16 × 2 sama dengan program arduino sehingga bekerja dengan baik, telah sesuai dengan yang diinginkan.

\section{Pengujian Kontaktor}

Sistem kontrol pada rangkaian ini menggunakan kontaktor sebagai ON / OFF beban. Sebelum digunakan, Kontaktor ini diuji terlebih dahulu untuk mengetahui kondisi kontaktor yang akan digunakan dalam kondisi baik atau tidak. 


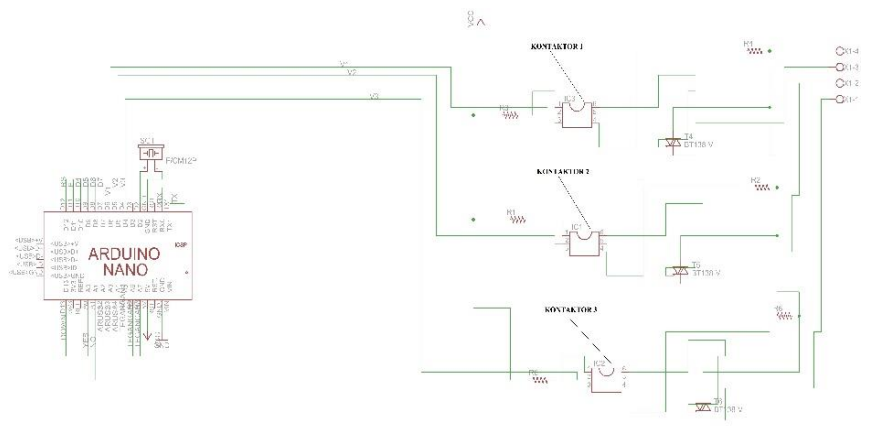

Gambar 5 Cicuit Kontaktor

Setelah dilakukan pengujian, kontaktor berfungsi dengan baik sehingga dapat bekerja dan telah sesuai dengan apa yang diinginkan

\section{Perangkat Lunak dan Aplikasi \\ Pengujian Program Arduino}

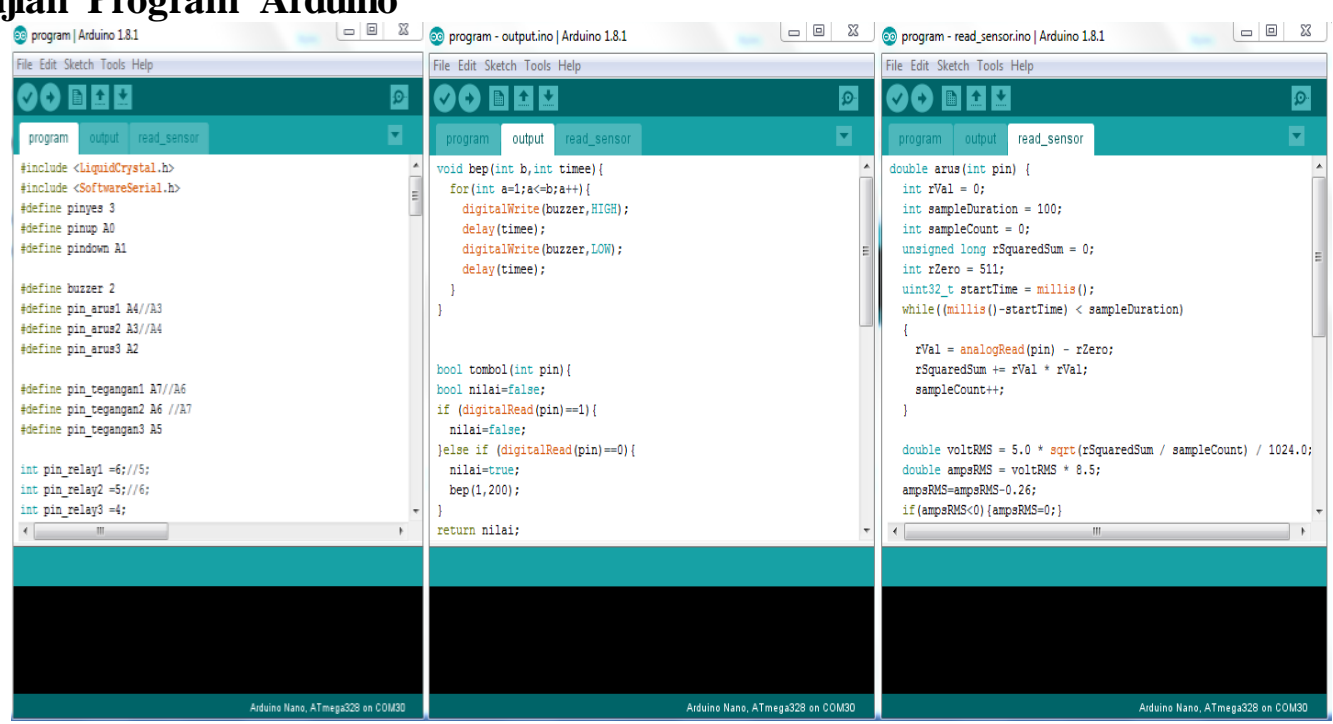

Gambar 6 Coding Bahasa Pemrograman Arduino

\section{Pengujian Program Visual Basic}

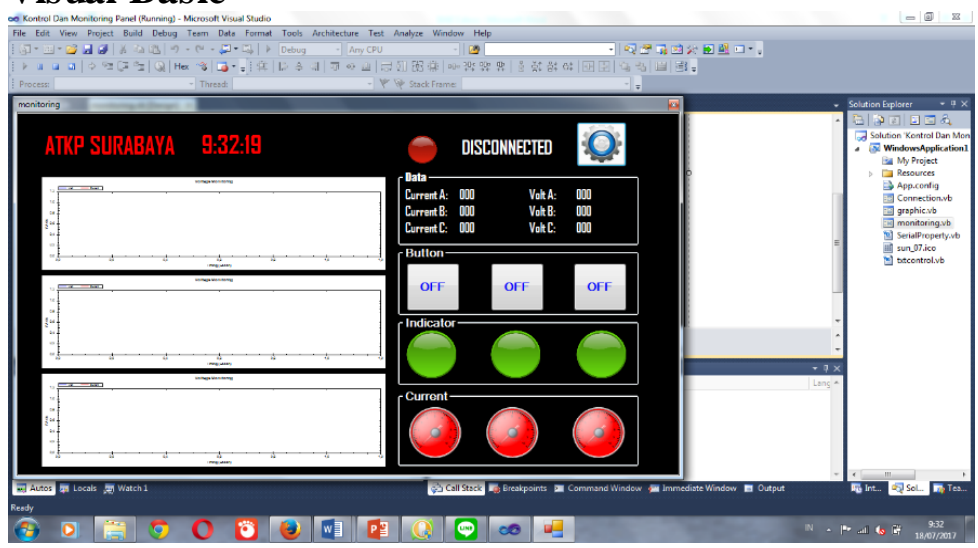

Gambar 6 Pengujian Tampilan Interface Visual Basic 


\section{Kesimpulan}

Dari implementasi sistem serta hasil pengujian dan pengukuran terhadap rancangan alat yang dibuat untuk tugas akhir ini yaitu tentang kontrol dan monitoring panel LVSDP (Low Voltage Sub Distribution Panel), dapat diambil kesimpulan sebagai berikut :

1. Kita dapat memonitoring arus dan tegangan pada beban yang masuk secara real time serta mengontrol beban mana yang harus ON dan mana yang harus OFF secara otomatis tanpa harus melakukan kontrol secara langsung ke tempat panel LVSDP (Low Voltage Sub Distribution Panel).

2. Kontrol ON / OFF beban serta monitoring arus dan tegangan dilakukan menggunakan tampilan interface memakai software Visual Basic dengan media PC (Personal Computer).

3. Informasi data kontrol dan monitoring diolah oleh mikrokontroller Arduino Nano yang dikirim ke PC (Personal Computer) melalui serial komunikasi RS-232.

\section{Saran}

1. Untuk software kontrol dan monitoring bisa menggunakan nirkabel via smartphone android / gadget agar lebih praktis dan efisien, walaupun berada jauh dari tempat kontrol jadi teknisi listrik masih bisa memantau.

2. Software Interface sebaiknnya diberikan sistem Login Paswoord untuk mencegah orang orang yang tidak bertanggung jawab dalam mengoperasikan selain teknisi listrik.

3. Bisa ditambahkan indikator over load / over current serta parameter daya yang mengalir ke beban dalam software interface, karena pada rancangan ini hanya ada parameter arus dan tegangan.

\section{Daftar Pustaka}

Akademi Teknik dan Keselamatan Penerbangan Surabaya, 2012. Modul Dasar Komputer. Surabaya : ATKP SURABAYA.

Akademi Teknik dan Keselamatan Penerbangan Surabaya, 2012. Modul Sistem Kendali Otomatis. Surabaya : ATKP SURABAYA.

Andrianto, Heri, dan Aan Darmawan. 2016. Arduino Belajar Cepat dan Pemrogaman. Bandung : Informatika.

Djuandi, Feri. 2011. Pengenalan Arduino. Jakarta : Elexmedia

Frank D.Petruzella, 2010, Elektronik Industri, Yogyakarta : Citra Laksana

Santoso, Hari. 2015. Arduino Untuk Pemula. Trenggalek : Ebook Elang Sakti. Sianipar, Bonar S.H. 2011. Modul Institut Sepuluh Nopember: Visual Basic 10.

Surabaya : Institut Sepuluh Nopember.

Stalling, William. 2001. Komunikasi Data \& Komputer. Jakarta : Penerbit

Salemba Tenika

Datasheet ACS712. Rev. 15, November 2012. Diambil dari :

http://www.alldatasheet.com/datasheet-pdf/pdf/168326/ALLEGRO/ACS712.html. (10

Februari 2017) 